BY NC ND

Estudos Teológicos foi licenciado com uma Licença Creative Commons Atribuição - NãoComercial - SemDerivados 3.0 Não Adaptada

http://dx.doi.org/10.22351/et.v58i1.3033

\title{
A IDENTIDade JUdaica e SUAS fronteiras no relato de Hecateu de Abdera ${ }^{1}$
}

\author{
The Jewish identity and its limits \\ in Hecataeus of Abdera's narrative
}

\section{Willibaldo Ruppenthal Neto ${ }^{2}$ Renan Frighetto ${ }^{3}$}

\begin{abstract}
Resumo: O presente artigo visa apresentar o relato de Hecateu de Abdera a respeito dos judeus, preservado em uma citação de Diodoro Sículo (Bibliotheca Historica, 40.3) e conservado por Fócio (Bibliotheca, 244), enfatizando a identidade judaica e suas fronteiras apresentadas neste, evidenciando não somente a caracterização grega dos judeus como ainda as transformações dentro da própria identidade judaica durante o período helenístico. Mediante a tradução e análise do referido relato, podem-se perceber elementos da cultura judaica que foram ressaltados por parte do autor grego que não eram tão presentes na autoconcepção judaica (a exemplo da educação militarizada), enquanto outros elementos como o sábado, a circuncisão e a monarquia, tão valorizados como marca identitária pelos próprios judeus, se encontram ausentes no relato.
\end{abstract}

Palavras-chave: Hecateu de Abdera. Mundo helenístico. Judaísmo.

Abstract: This article aims to present the narrative of Hecataeus of Abdera about the Jews, quoted by Diodorus Siculus (Bibliotheca Historica, 40.3) and preserved by Photius (Bibliotheca, 244), emphasizing the Jewish identity and its boundaries presented in this, showing not only the Greek characterization of the Jews but also the transformations within the Jewish identity itself during the Hellenistic period. Through the translation and analysis of the narrative, may be perceived that many elements of Jewish culture that was emphasized by the Greek author was not so important in the

1 O artigo foi recebido em 30 de maio de 2017 e aprovado em 11 de setembro de 2017 com base nas avaliações dos pareceristas ad hoc.

2 Mestre em História pelo Programa de Pós-Graduação em História da Universidade Federal do Paraná (2018). Graduado em História pela UFPR (2015) e bacharel em Teologia pelas Faculdades Batista do Paraná (2015). Professor do Bacharelado em Teologia EAD das Faculdades Batista do Paraná (FABAPAR), em Curitiba/PR, Brasil. Membro discente do NEMED/UFPR. Contato: willibaldoneto@hotmail.com

3 Doutor em História Antiga pela Universidade de Salamanca (1996), na Espanha; mestre em História Antiga e Medieval pela Universidade Federal do Rio de Janeiro (1990); professor associado da Universidade Federal do Paraná, em Curitiba/PR, Brasil - Departamento de História. Pesquisador 1D CNPq; pesquisador do NEMED/UFPR. Contato: rfrighetto@hotmail.com 
Jewish self-perception, while other elements like the Sabbath, the circumcision, and the monarchy, which was so estimated by the Jews as marks of identity, do not appear in the narrative.

Keywords: Hecataeus of Abdera. Hellenistic World. Judaism.

\section{Introdução}

Dentre os diversos textos gregos e latinos a respeito dos judeus e do judaísmo ${ }^{4}$, o relato de Hecateu de Abdera sobre os judeus em sua obra Aegyptiaka, preservado em uma citação na Bibliotheca Historica de Diodoro Sículo e conservado na Bibliotheca de Fócio $^{5}$, tem fundamental importância não somente por sua datação como ainda por sua extensão. Além de ser possível que Hecateu seja o primeiro autor grego a que temos acesso a relatar a respeito dos judeus, certamente foi "o primeiro autor grego a nos deixar uma descrição relativamente extensa do povo judeu" ". Em sua obra, escrita durante o período helenístico, com o propósito de estabelecer uma história do Egito para o rei Ptolomeu I Soter ${ }^{7}$, aparece uma descrição dos judeus a partir do êxodo do Egito, relatando não somente sua história, como ainda seus costumes, religião e mesmo sua organização política. Esse texto, portanto, é especialmente importante não somente por ser uma citação de Hecateu de Abdera, autor que "abriu uma nova era no campo da etnografia, assim como Tucídides antes dele iniciou uma nova era da historiografia", mas também por ser uma importante fonte na compreensão da caracterização da identidade judaica e suas fronteiras a partir do ponto de vista grego, no início do período helenístico.

\section{O relato de Hecateu de Abdera sobre os judeus}

Para se compreender como exatamente se apresenta a identidade judaica e mesmo suas fronteiras no relato de Hecateu de Abdera sobre os judeus, segue abaixo uma tradução de nossa autoria ${ }^{9}$ :

4 A respeito das referências aos judeus e ao judaísmo por autores gregos e latinos, não há referência melhor que a monumental obra de Menahem Stern (1976-1984), que traz não somente os textos desses autores como ainda importantes introduções e comentários: STERN, Menahem. Greek and Latin Authors on Jews and Judaism. Edited with Introductions, Translations, and Commentary by Menahem Stern. Jerusalem: Israel Academy of Sciences and Humanities. 3 v.: 1976 (I); 1980 (II); 1984 (III).

5 Hecateu de Abdera. Aegyptiaka; Diodorus Siculus, Bibliotheca Historica, 40.3; Fócio, Bibliotheca, 244.

6 BAR-KOCHVA, Bezalel. The Image of the Jews in Greek Literature: The Hellenistic Period. Berkeley: University of California Press, 2010. p. 90.

7 Flávio Josefo, (Cont. Ap., 1.183) relata que Hecateu viveu no tempo de Ptolomeu I. Sobre a relação de Hecateu com Ptolomeu e o propósito da sua obra, cf. MURRAY, Oswyn. Hecataeus of Abdera and Pharaonic Kingship. Journal of Egyptian Archaeology, v. 56, p. 141-171, Aug. 1970.

8 BAR-KOCHVA, 2010, p. 96.

9 A presente tradução utiliza como base as traduções comentadas presentes em: WALTON, F. R. Diodorus of Sicily. Cambridge, Mass.; London: Harvard University Press, 1967. v. 12, p. 281-283; STERN, 1976, 
[1] Em tempos antigos, quando uma peste se alastrou pelo Egito, o povo simples atribuiu a causa de seus males à intervenção divina, pois, como havia muitos estrangeiros, de todas as partes do mundo, que viviam no meio deles e tinham diferentes costumes a respeito da religião e dos sacrifícios, seu próprio culto ancestral dos deuses deixou de ser observado.

[2] Por causa disso, os nativos da terra entenderam que, a menos que os estrangeiros fossem removidos, seus problemas não seriam resolvidos. Imediatamente, então, os forasteiros foram banidos daquela terra, tendo os mais distintos e competentes se juntado em grupos que foram expulsos, alguns dizem, para a Grécia e outros lugares, estando sob líderes notáveis, dos quais os mais famosos são Dânao e Cadmo. A maioria, porém, se dirigiu ao que hoje se chama Judeia, que não é distante do Egito e que naquele tempo se encontrava completamente desabitada.

[3] A colônia foi liderada por um homem chamado Moisés, que era notável em prudência e em bravura. Tomando posse da terra, ele fundou muitas cidades, dentre as quais aquela que atualmente é a mais famosa de todas, chamada Jerusalém. Ele também construiu o Templo, pelo qual eles têm a maior veneração, instituiu as formas de adoração à divindade e seus rituais, e estabeleceu a forma de sua constituição. Ele também os dividiu em doze tribos, por considerar esse como o número mais perfeito e correspondente ao número de meses que formam o ano.

[4] Mas ele não fez qualquer imagem de divindade, pois ele acreditava que deus não possuía forma humana, mas que apenas o céu, ao redor da terra, é o único deus e senhor de tudo. Ele estabeleceu sacrifícios e um estilo de vida que diferem daqueles dos demais povos, pois como resultado de sua própria expulsão ele introduziu um modo de vida antissocial e inospitaleiro. Ele escolheu os homens mais talentosos e mais capazes para liderarem todo o povo, os quais nomeou como sacerdotes, e prescreveu que deveriam se ocupar no cuidado do Templo e na adoração e sacrifícios à divindade.

[5] Ele também apontou esses mesmos homens como juízes para os casos mais importantes, e lhes confiou a guarda da lei e dos costumes. E por isto nunca (houve) um rei dos judeus, mas a liderança da população é sempre confiada ao sacerdote em que for encontrado maior prudência e virtude. Eles chamam esse homem de sumo sacerdote e acreditam que ele se torna um mensageiro dos mandamentos do deus para eles.

[6] É ele quem, nas assembleias e em outras reuniões, pelo que é dito, proclama o que é ordenado, e que tem dos judeus tanta obediência nesse aspecto, que eles imediatamente se prostram ao chão e fazem reverência ao sumo sacerdote enquanto esse interpreta (a lei) para eles. Até mesmo está anexado no final de suas leis a declaração: "Quando Moisés ouviu de Deus estas coisas, as disse aos judeus". O legislador dedicou muita atenção às questões militares, forçou os jovens à prática da bravura e da resistência, e de modo geral, ao fortalecimento em toda dificuldade.

p. 26-35 (tradução de Walton com um excelente e extenso texto de comentário); REINACH, Théodore. Textes d'auteurs grecs et romains relatifs au judaïsme. Reunis, traduits et annotés par Théodore Reinach. Paris: Ernest Leroux, 1895. p. 14-20 (tradução francesa); WHITTAKER, Molly. Jews and Christians: Graeco-Roman Views. Cambridge: Cambridge University Press, 1984. p. 36-38; AUSTIN, M. M. The Hellenistic World from Alexander to the Roman Conquest: A selection of ancient sources in translation. Second augmented edition. Cambridge: Cambridge University Press, 2006. p. 378-380; BAR-KOCHVA, Bezalel. Pseudo-Hecataeus, "On the Jews": Legitimizing the Jewish Diaspora. Berkeley: University of California Press, 1996. p. 19-21; BAR-KOCHVA, 2010, p. 100-103. 
[7] Ele realizou expedições militares às terras dos povos vizinhos e, tendo conquistado muitas terras, repartiu as terras conquistadas entre a população, prescrevendo loteamentos iguais aos cidadãos comuns, mas concedendo lotes maiores aos sacerdotes que, recebendo maiores rendimentos, podiam concentrar-se e cuidar continuamente do culto do deus. Não era permitida aos cidadãos comuns a venda de seus lotes, a fim de que não houvesse alguns que, comprando-os gananciosamente, oprimissem assim os pobres e causassem uma diminuição na população.

[8] Ele forçou os que viviam na terra a criarem seus filhos, e como as crianças podiam ser criadas por baixos custos, o povo dos judeus foi sempre populoso. Práticas relativas ao casamento e ao enterro dos mortos foram vistas por ele como tendo que ser bastante diferentes daquelas do resto da humanidade.

\section{Proximidade e distanciamento com o relato judaico}

Há, no relato de Hecateu, quatro equívocos em relação à história judaica que se sobressaem, tal como listados por Daniel R. Schwartz ${ }^{10}$ : 1) Canaã ser desabitada quando os judeus chegaram $(40.3 .2)^{11}$; 2) Moisés ter fundado Jerusalém e construído o Templo $(40.3 .3)^{12}$; 3) Moisés ter dividido o povo em doze tribos e entregue a lei depois

${ }^{10}$ SCHWARTZ, Daniel R. Diodorus Siculus 40.3 - Hecataeus or Pseudo-Hecataeus? In: MOR, Menahem et al. (eds.). Jews and Gentiles in the Holy Land in the Days of the Second Temple, the Mishnah and the Talmud: a collection of articles. Jerusalem: Yad Ben-Zvi, 2003. p. 193-194.

${ }^{11}$ Segundo os livros de Josué e Juízes, a terra na qual os judeus se estabelecem, Canaã, é a habitação de povos que são derrotados e mortos pelos judeus invasores. A designação "cananeus" é utilizada na Bíblia Hebraica como referência ao conjunto dos povos que habitavam Canaã antes da entrada dos judeus, sendo o termo étnico mais utilizado na Bíblia, e sendo alvo tanto da determinação do extermínio (Dt 7.1-2; 20.16-18) como de sua realização. Lisímaco chega a utilizar esse extermínio como mecanismo apologético contra os judeus (Flávio Josefo. Cont. Ap., 1.310; STERN, 1976, p. 158). Sobre os cananeus, cf. NA'AMAN, Nadav. The Canaanites and their Land: A Rejoinder. In: DIETRICH, Manfried; LORETZ, Oswald (Hg.). Sonderdruck aus Ugarit-Forschungen: Internationales Jahrbuch für die Altertumskunde Syrien-Palästinas. Neukirchen-Vluyn: Butzon \& Bercker, 1994. p. 397-418.

${ }^{12}$ Segundo o relato bíblico, a cidade de Jerusalém (Salém) existia muito antes do tempo de Moisés, já no período dos patriarcas (Gn 14.18-20; 22.1-19), tendo sido incorporada a Israel pela conquista do rei Davi ( $2 \mathrm{Sm} 5 ; 1 \mathrm{Cr} 11)$. Apesar da importância fundamental da cidade na história do judaísmo, "não há uma única tradição narrativa na Bíblia Hebraica sobre a fundação de Jerusalém” (BOLIN, Thomas M. The Making of the Holy City: on the foundations of Jerusalem in the Holy Bible. In: THOMPSON, Thomas L. (ed.). Jerusalem in Ancient History and Tradition. London; New York: T\&T Clark International, 2003. p. 179). A construção do Templo de Jerusalém é creditada no relato bíblico ao rei Salomão, filho de Davi (1Rs 6 -7). É bem possível que o relato seja uma construção ideológica deuteronomística a fim de estabelecer uma continuidade entre Davi e Salomão. Cf. VAN SETERS, John. Solomon's Temple: Fact and Ideology in biblical and Near Eastern Historiography. Catholic Biblical Quarterly, v. 59, n. 1, p. 45-57, Jan. 1997. 
de entrar na Judeia $(40.3 .3)^{13}$; 4) os judeus nunca terem tido um rei $(40.3 .5)^{14}$. Mesmo assim, porém, não se pode ignorar o evidente reflexo de histórias bíblicas no relato, mesmo que adaptadas e reformuladas, a exemplo do êxodo do Egito à terra prometi$\mathrm{da}^{15}$, do papel de Moisés como legislador, da conquista de Canaã ${ }^{16}$, do papel central de Jerusalém e do Templo, da proibição de imagens para adoração ${ }^{17}$, da divisão em doze tribos, do papel dos sacerdotes como intérpretes da Torá, do sumo sacerdócio, das restrições à venda de terras ${ }^{18}$, da tendência ao aumento populacional ${ }^{19}$, dentre outras.

Apesar da saída dos judeus do Egito ser um relato presente dentro da própria cultura judaica, tal como se pode perceber no livro de Êxodo - o segundo livro da Bíblia Hebraica (Tanakh), o mesmo aparece na obra de Hecateu um tanto quanto distante da tradição bíblica judaica. Diferente do relato do Êxodo no qual os judeus decidem sair do Egito ${ }^{20}$, recebendo a liberdade por parte do Faraó após as dez pragas (ou maravilhas $^{21}$ ) enviadas por Deus para castigar os egípcios ${ }^{22}$, no relato de Hecateu a partida dos judeus se dá enquanto uma expulsão, por parte dos próprios egípcios, de todos os estrangeiros, dentre os quais - de um valor inferior, diga-se de passagem - os judeus. A aferição da peste à intervenção divina é feita pelo "povo simples", desvalorizando tal perspectiva $(40.3 .1)^{23}$, assim como o estabelecimento dos judeus na Palestina não

13 Segundo a Torá ("Lei", entenda-se: os cinco primeiros livros, também conhecidos como Pentateuco), a divisão do povo de Israel em 12 tribos teria como origem os 12 filhos de Jacó (Gn 35.23-26; 48), patriarca e neto de Abraão, a quem Deus dá o nome de "Israel" (Gn 32.28). Também segundo a Torá, ao final do livro de Deuteronômio (34) é relatada a morte de Moisés no monte Nebo, sem que esse tenha entrado na terra prometida. A lei mosaica, portanto, não é entregue no território da Judeia, mas durante a peregrinação no deserto. A respeito dos textos bíblicos que apresentam o sistema de 12 tribos israelita, cf. KALLAI, Zecharia. The Twelve-Tribe Systems of Israel. Vetus Testamentum, v. 47, Fasc. 1, p. 53-90, Jan. 1997.

${ }^{14}$ É evidente que os judeus tiveram reis, conforme os relatos dos livros de 1 e 2 Samuel, 1 e 2 Reis e 1 e 2 Crônicas. Apesar do primeiro rei ser, segundo a tradição, Saul, somente a partir de Davi surge uma verdadeira linha dinástica, que dá origem a uma expectativa messiânica baseada na linhagem davídica.

15 Transmitido especialmente no livro de Êxodo.

${ }^{16}$ Apesar de 40.3.2 afirmar que o território da Judeia estava desocupado, 40.3.7 afirma que foram empreendidas expedições militares para a conquista de terras na região (por Moisés).

17 Além da proibição da fabricação de imagens para adoração (Êx 20.3-5; Lv 26.1), essas devem ser destruídas (Dt 7.25-26). A proibição se dá pelo fato de que as imagens concorrem com Deus pela adoração (Dt 7.4-5; 8.19-20), ao mesmo tempo em que são biblicamente desprezadas como meros "ídolos", que não devem ser adorados (Dt 11.16-17), nem receber sacrifícios (Sl 106.38), pois são objetos sem poder (Is 40.19-20).

${ }^{18}$ Lv 25.25-34; Nm 26.54; 1Rs 21.3-4.

${ }^{19}$ A bênção divina "sede fecundos e multiplicai-vos" aparece ao longo do processo de criação $(1.22 ; 3.16)$ e é repetida após a salvação do dilúvio (Gn 9.7). Seu cumprimento se dá ao longo da história (Gn 47.27; Êx 1.7) e é retomada como bênção pelos profetas (Jr 3.16; 23.3; Ez 36.11).

${ }^{20}$ A saída do Egito parte da iniciativa dos próprios judeus, liderados por Moisés, que segue o comando divino.

${ }^{21}$ As dez pragas, descritas em Êxodo (7.14 - 12.36), são indicadas como um meio de Deus mostrar seu poder aos povos da terra (Êx 9.15-16), sendo, portanto, "maravilhas" (hamōpetîm), cf. Êx 4.21; 7.3,9; 11.9-10. Seu caráter é positivo aos judeus, que além de escaparem às pragas, receberam a liberdade a partir dessas.

${ }^{22}$ Segundo Êxodo 12.12, o julgamento de Deus não somente caiu sobre os egípcios como ainda sobre seus deuses e animais.

${ }^{23}$ Ao mesmo tempo, afirmar que 40.3.1 é um relato dos judeus como "vítimas da superstição e barbárie dos egípcios" (SCHWARTZ, 2003, p. 191) nos parece um tanto quanto exagerado. 
é indicado como uma conquista militar guiada por Deus ao seu povo liberto do Egito, tal como no relato bíblico, mas enquanto uma fundação de uma colônia ${ }^{24}$ do Egito com costumes bastante peculiares e uma constituição idealizada ${ }^{25}$. Assim, apesar da influência do relato do Êxodo estar presente, esse é apresentado a partir de elementos gregos que podem indicar: a interpretatio graeca de $\mathrm{Hecateu}^{26}$, sua ignorância a respeito da cultura judaica ${ }^{27}$, ou ainda a influência de judeus egípcios que teriam alterado o relato do Êxodo aos moldes gregos ${ }^{28}$.

\section{A religião judaica no relato de Hecateu}

A afirmação de Hecateu sobre a religião dos judeus deixa claro que ele possui um conhecimento relativo da mesma, ao mesmo tempo em que lhe dá uma significação racional. Quando afirma que Moisés "não fez qualquer imagem de divindade, pois ele acreditava que deus não possuía forma humana" (40.3.4), demonstra um conhecimento razoável da religiosidade judaica, mas que é logo em seguida posto em dúvida pela justificação de tal ausência de imagens pelo fato de que Moisés "acreditava que deus não possuía forma humana, mas que apenas o céu, ao redor da terra, é o único deus e senhor de tudo" (40.3.4). É evidente que o aspecto abstrato do Deus dos

${ }^{24}$ Como bem lembra BAR-KOCHVA(2010, p. 124), apoikia significa literalmente "um assentamento distante de casa", usualmente se referindo a assentamentos voluntários, mas ocasionalmente indicando exílios. Nesses sentidos, cf. Píndaro, Odes, 1.24; Sófocles, Ichneutae, 373.6; Heród. Hist., 1.146. Esse termo, porém, ao longo do tempo mudou de sentido, vindo a significar somente "assentamento", cf. Dion. Hal., Ant. rom., 2.2.4. No caso de Hecateu, apesar de ser provável o uso no sentido de uma "colônia egípcia", difere das colônias usuais pelo fato de que os judeus já eram estrangeiros (allophýlous) no Egito (40.3.1).

${ }^{25} \mathrm{O}$ aspecto aristocrático das descrições de Moisés e dos sacerdotes parece remeter ao Estado utópico platônico, de modo que os sacerdotes se assemelham aos "regentes" da República de Platão (HENGEL, Martin. Judaism and Hellenism: Studies in their Encounter in Palestine during the Early Hellenistic Period. Philadelphia: Fortress, 1974. v. 1, p. 256), e o privilégio dos mais habilidosos reflete aspectos aristotélicos (cf. Arist., Pol., 1279a34, 1293b1-6, 1294a9; Eth. Nic., 1095a18-19,22b). Cf. BAR-KOCHVA, 2010, p. 125; JAEGER, Werner. Greeks and Jews: The first Greek records of Jewish religion and civilization. Journal of Religion, v. 18, n. 2, p. 127-143, April 1938. p. 141ss.

${ }^{26}$ BAR-KOCHVA, 1996, p. 26.

${ }^{27}$ STERN, 1976, p. 31.

${ }^{28}$ GRUEN, Erich S. The Use and Abuse of the Exodus Story. Jewish History, v. 12, n. 1, p. 93-122, Spring 1998. Erich S. Gruen indica que o relato de Hecateu deve ter tido a influência de uma "comunicação oral com judeus egípcios" (GRUEN, 1998, p. 101), de modo que "seria um erro grosseiro assumir que intelectuais judeus aderiram rigidamente ao conto do Êxodo como esse aparece na Bíblia e que desvios desse representem manipulação por gentios. Variantes da história devem de fato mais à ingenuidade judaica do que nós costumamos conceder" (GRUEN, 1998, p. 102). Sobre a adaptação da história do Êxodo, cf. também GAGER, John G. Some Thoughts on Greco-Roman Versions of the Exodus Story. Jewish History, v. 12, n. 1, p. 129-132, Spring 1998. É digno de nota que mesmo Jan Bremmer, que defende que Hecateu teve judeus como fonte, indica o seu relato do êxodo como decorrente da "influência dos egípcios, provavelmente sacerdotes" (BREMMER, Jan N. Spartans and Jews: abrahamic cousins. In: GOODMAN, Martin; VAN KOOTEN, George H.; VAN RUITEN, Jacques T. A. G. M. Abraham, the Nations, and the Hagarites: Jewish, Christian, and Islamic perspectives on Kinship and Abraham. Leiden: Brill, 2010. p. 48), porém admite o uso de fontes judaicas pelo texto de 40.3.6, que parece fazer eco a Deuteronômio 29.1, de modo que a expressão "o fim de suas leis" pode ser uma referência ao conjunto do Pentateuco como um todo (BREMMER, 2010, p. 49). 
judeus era dificilmente compreendido pelos gregos, até porque, como bem indicado por Nachman Falbel, "sem dúvida, o deus abstrato dos judeus, não configurado, é o maior obstáculo para o entendimento da religião judaica pelos politeístas"29. Assim, a afirmação de Hecateu de que os judeus veneravam o próprio Céu parece ser uma interpretação grega sobre a abstração divina dos judeus, e que parece ganhar um certo aspecto filosófico ${ }^{30}$, transformando-se no Céu como elemento da natureza (phýsis), enquanto o Céu "que circunda a terra" 31 .

Possivelmente essa perspectiva de Hecateu foi decorrente do contato com os próprios judeus, que utilizavam os "Céus" como meio de se referir a Deus, a fim de não falarem o nome de Deus em vão ${ }^{32}$, mas de modo algum aludindo à proeminência dos céus como elemento divino na natureza, em sentido filosófico. Ao mesmo tempo, é digno de destaque que com essa afirmação Hecateu se coloca em uma linha de interpretação filosófica ${ }^{33}$ a respeito das religiões orientais, seguindo Heródoto e precedendo Estrabão. Heródoto, quando descreve a religião dos persas, o faz da seguinte forma:

Eu sei que os persas possuem estes costumes: não é de seu costume erigirem estátuas, templos, e altares, e atribuem loucura a estes que o fazem porque, como me parece, eles, diferente dos gregos, não consideram os deuses como tendo natureza humana. Eles vão ao topo das montanhas e fazem sacrifícios a Zeus, chamando Zeus ao círculo do céu $[\ldots]^{34}$.

A semelhança entre essa passagem e 40.3 .4 não é apenas interessante como sugestiva: sabendo-se da evidente influência de Heródoto em Hecateu, não é de se estranhar que "a explicação causal usada por Heródoto reaparece em Hecateu"35, ou

${ }^{29}$ FALBEL, Nachman. Raízes do anti-semitismo na Antiguidade e na Idade Média. In: FUKS, Saul (Org.). Tribunal da história. Rio de Janeiro: Imago; Centro de História e Cultura Judaica, 2008. v. 2: Processos de formação da identidade judaica e do anti-semitismo, p. 201.

${ }^{30}$ É evidente que Hecateu tinha "interesses tanto filosóficos como históricos" (GRUEN, 1998, p. 99), de modo que tanto a filosofia grega como a teoria política grega influenciaram sua perspectiva sobre os judeus. Cf. GRUEN, 1998, p. 101. Aqui, o elemento filosófico é evidente, especialmente quando se compara com Demócrito (também de Abdera), que disse que o primeiro homem a fundar a religião, "ergueu suas mãos àquele lugar que nós gregos chamamos de casa do ar e disse que Zeus discute todas as coisas e que ele sabe todas as coisas e tira e é o rei de tudo" (Demócrito, B30 Diels). Cf. JAEGER, 1938, p. 133.

${ }^{31}$ Teofrasto afirma que os judeus contemplam o céu enquanto conversam sobre o divino. Essa afirmação, assim como a de Hecateu, parece aludir às ideias de Platão (De Leg., 12.966d-e) e Aristóteles (Frag. 10), de que os corpos celestes são uma demonstração da existência divina. Werner Jaeger chamará tal aplicação filosófico-teológica do céu como "astroteologia" (JAEGER, 1938, p. 133).

32 A ordem divina para que o nome de Deus não seja tomado em vão (Êx 20.7) leva os judeus a terem uma postura bastante cuidadosa em relação às referências a Deus. Cf. Dt 28.58. A expressão "Deus dos céus" aparece tanto no decreto de Ciro (Ed 1.2) como no papiro de Elephantine. No caso de 1 Macabeus, há o uso do termo "céus", ao invés de "Deus", como destaca BREMMER (2010, p. 58). Cf. 1Mac 3.18-19, 50,$60 ; 4.10,24,40,55 ; 9.46 ; 12.15 ; 16.3$. Possivelmente a expressão "reino dos céus" ao invés de "reino de Deus" no Evangelho de Mateus seja decorrente desse cuidado.

${ }^{33} \mathrm{O}$ aspecto filosófico de Hecateu não deve ser desconsiderado, uma vez que era discípulo de Pirro, e possivelmente é o "Hecateu, o sofista".

${ }^{34}$ Heród., Hist., 1.131.1-2. Seguimos a tradução em: BAR-KOCHVA, 2010, p. 133 (abreviada).

${ }^{35}$ BAR-KOCHVA, 2010, p. 133. 
seja, a explicação da ausência de imagens pela adoração do próprio céu. Essa mesma ideia é retomada por Estrabão:

Um sacerdote egípcio chamado Moisés [...] declarou e ensinou [...] que os gregos também estavam errados em fazer imagens de seus deuses em forma humana. Pois apenas este é Deus: o que cerca todos nós assim como a terra e o mar, [aquilo] que chamamos de céu, de cosmo, e de natureza de todas as coisas $[\ldots]^{36}$.

É bem possível que Estrabão tenha utilizado Hecateu como fonte para essa informação ${ }^{37}$, porém é igualmente possível que ambos façam parte de uma linha interpretativa que vai além de Hecateu, tendo Posidônio como fonte intermediária ${ }^{38}$, e conferindo um caráter estoico à representação da religião dos judeus. ${ }^{39}$ Assim, a explicação causal de Hecateu parece ser desenvolvida posteriormente como uma racionalização filosófica da particularidade judaica. ${ }^{40}$

\section{A identidade judaica e suas fronteiras nas ausências do relato}

Tão importantes quanto os elementos que aparecem no relato de Hecateu, porém, são os elementos ausentes no mesmo. Dentre as diversas ausências no relato de Hecateu, três certamente se destacam: a ausência de menções às práticas da circuncisão e do shabbat, e a negação da existência de uma monarquia na história dos judeus.

Em nenhum momento Hecateu se refere à circuncisão em seu relato sobre os judeus. Apesar do autor fazer uma lista dos costumes judaicos, não apresenta essa prática entre eles. Dificilmente essa omissão decorreu da citação de Diodoro, uma vez que, "residindo em Roma, dificilmente teria omitido um costume que os romanos achavam tão deplorável" quando se toma em conta que "os escritores gentios frequentemente demonstravam um interesse na circuncisão"42. Como explicar essa ausência? Sendo bem conhecido

${ }^{36}$ Estrabão, Geog., 16.2.35. Seguimos a tradução em: LUDLAM, Ivor. Appendix: The God of Moses in Strabo. In: BAR-KOCHVA, Bezalel. The Image of the Jews in Greek Literature: The Hellenistic Period. Berkeley: University of California Press, 2010. p. 525 (abreviada).

${ }^{37}$ A respeito de Hecateu como fonte de Estrabão, cf. BAR-KOCHVA, 2010, p. 356n1, 363-364, 376, 379; LUDLAM, 2010, p. 534-535; GAGER, 1972, p. 41.

${ }_{38}$ LUDLAM, 2010, p. 535-541. Cf. Tácito, Hist., 5.5.4.

39 Os estoicos acreditavam que só há um deus, ao mesmo tempo em que não negavam os deuses gregos, enquanto representações várias de um mesmo deus.

${ }^{40}$ Como bem indicado por Werner Jaeger, já Aristóteles definia os sistemas religiosos orientais como "sabedoria" (sophía), que será na filosofia aristotélica a designação para o conhecimento metafísico dos princípios primeiros, ou teologia. Cf. JAEGER, 1938, p. 129. Não será à toa, portanto, o aumento do interesse da academia de Platão na metafísica dualística do Zoroastrismo, por exemplo. Cf. JAEGER, 1938, p. 130. Também a astrologia dos caldeus era tida em alta conta nesse sentido.

41 BAR-KOCHVA, 2010, p. 110.

42 SCHWARTZ, 2003, p. 186. Isso é bem evidente no grande número de menções à circuncisão entre os autores gregos e latinos, conforme se pode perceber na listagem presente no índice da grande obra de Menahem Stern, cf. STERN, 1984, p. 114 (v. "Circuncision”), como bem lembrado por SCHWARTZ (2003, p. 186n13). 
entre os gregos o fato de que a circuncisão era praticada por sacerdotes egípcios, geralmente se aferia que a presença dessa prática em outros povos era sinal de uma influência cultural egípcia. Ora, estando o relato dos judeus dentro de um contexto de crítica à teoria egípcia de que o Egito era a fonte de todas as civilizações, é bem possível que Hecateu, tendo selecionado do material à sua disposição aquilo que entendeu como útil ${ }^{43}$, deixou a circuncisão de lado, justamente porque essa indicaria, no contexto do relato egípcio, não um distanciamento, mas antes uma aproximação e mesmo uma vinculação entre judeus e egípcios, ou seja, seria um contra-argumento. Dessa forma, apesar da circuncisão ser para os próprios judeus como a grande fronteira cultural que possuíam em relação aos "gentios" 44 , sendo tida como sua marca identitária por excelência ${ }^{45}$, para Hecateu é antes um ponto em comum com os egípcios, cuja menção é evitada. ${ }^{46}$ Cabe destacar, porém, que no período dos macabeus (séc. II a.C.), após Hecateu, a circuncisão passa a ser assumida de tal forma pelos judeus, que não somente se torna um símbolo identitário ainda mais forte para esses ${ }^{47}$, como também passa a ser a grande marca da cultura judaica para os próprios gentios ${ }^{48}$, tornando-se tanto o alvo de proibições por parte dos gentios como ainda a causa das revoltas decorrentes de tais proibições. ${ }^{49}$

${ }^{43}$ BAR-KOCHVA, 2010, p. 115. Cf. Diod. Sic., Bib. Hist., 1.69.2; 1.72.6.

${ }^{44}$ Os filisteus eram denominados "incircuncisos" (arelim, literalmente "com prepúcio") na Bíblia Hebraica (cf. Jz 14.3; 15.18; $1 \mathrm{Sm} 14.6 ; 17.26,36 ; 18.27 ; 31.4 ; 2 \mathrm{Sm} \mathrm{1.20;} \mathrm{3.14;} \mathrm{1Cr} \mathrm{10.4),} \mathrm{porém,} \mathrm{segundo} \mathrm{Avraham}$ Faust, esses deixam de ser chamados assim a partir do período monárquico (Ferro II), uma vez que a cultura filisteia já havia se transformado e incorporado essa prática. Cf. FAUST, 2015. Soma-se ainda o fato de que na literatura rabínica antiga mesmo os não judeus circuncidados eram denominados como "incircuncisos". Cf. STERN, Sacha. Jewish Identity in Early Rabbinic Writings. Leiden: E. J. Brill, 1994. p. 60.

${ }^{45}$ Sobre a circuncisão como marca identitária, cf. NIEHOFF, Maren R. Circumcision as a marker of identity: Philo, Origen and the Rabbis on Gen 17:1-4. Jewish Studies Quarterly, v. 10, n. 2, p. 89-123, 2010.

${ }^{46}$ Bezalel Bar-Kochva lembra que "nem ele [Hecateu] nem seus leitores tomavam a circuncisão como peculiarmente judaica" (BAR-KOCHVA, 2010, p. 115). Certamente a associação da circuncisão aos egípcios se dava pela ampla leitura de Heródoto, que já havia indicado tal prática como a evidência de uma influência egípcia entre os sírios da Palestina (Heródoto, Hist., 2.104.1-3). Acontece, porém, que essa associação ganha força na antiguidade, com outro relato do próprio Hecateu (Diod. Sic., Bib. Hist., 28.1-3). A força dessa associação é tal, que Sigmund Freud chega a defender a tese de que Moisés era um egípcio, tendo esse ponto como base. Cf. FREUD, Sigmund. Moisés e a religião monoteísta. Tradução Paulo Samuel. Lisboa: Guimarães, 1990. p. 44ss.

${ }^{47}$ Segundo Shaye J. D. Cohen, a circuncisão somente se torna "a marca essencial da identidade israelita" após o período macabeu. Cabe lembrar que no contexto macabeu os judeus helenizantes foram acusados de tentar esconder sua circuncisão (1Mac 1.15), assim como a dinastia dos asmoneus adota a política da circuncisão forçada dos povos vizinhos conquistados. Cf. COHEN, Shaye J. D. From the Maccabees to the Mishnah. 2. ed. Louisville: Westminster John Knox, 2006. p. 43-44; DABROWA, Edward. The Hasmoneans and the Religious Homogeneity of their State. Scripta Judaica Cracoviensia, Krákow, v. 8 , p. 7-14, 2010.

${ }^{48}$ Cf. SCHÄFER, Peter. Judeophobia: Attitudes toward the Jews in the Ancient World. Cambridge: Harvard University Press, 1997. p. 95ss.

49 Após a proibição da circuncisão (e outras práticas judaicas) pelo rei selêucida Antíoco IV, os judeus respondem com a Revolta dos Macabeus. Cf. DORAN, Robert. The Persecution of Judeans by Antiochus IV: The Significance of "Ancestral Laws". In: HARLOW, Daniel C. et al. The "Other" in Second Temple Judaism: Essays in Honor of John J. Collins. Grand Rapids: Eerdmans, 2011. p. 423-433. Também, após a proibição da circuncisão pelo imperador Adriano, ocorre a Revolta de Bar Kochba. Cf. SMALLWOOD, 
A ausência de referências ao shabbat ${ }^{50}$, porém, necessita de outra explicação, uma vez que esse costume "mais do que quase todos os demais, teria ajudado Hecateu a enfatizar a exclusividade judaica" ${ }^{51}$. Provavelmente, portanto, não se deu enquanto ausência proposital de Hecateu, mas antes por seu desconhecimento a respeito da particularidade desse costume judaico. Isto implica, segundo Bar Kochva, que o texto data de antes da captura de Jerusalém por Ptolomeu I, que se deu justamente em um sábado. ${ }^{52}$ Ora, a peculiaridade do shabbat era particularmente importante pelo proveito militar que ela oferecia, uma vez que os judeus ficaram conhecidos por não lutarem no dia de sábado ${ }^{53}$, assim como em dias festivos, ou mesmo nos anos sabáticos. ${ }^{54}$ Não é à toa, portanto, que o livro de 1 Macabeus, apesar de se referir aos mártires que guardaram o dia santo (1Mac 2.29-38) ${ }^{55}$, coloca Matatias como aquele que propõe a luta mesmo em dia de sábado (1Mac 2.39-41) ${ }^{56}$. O shabbat é, portanto, um importante elemento tanto na afirmação identitária judaica como na definição de limites, uma vez que, apesar dos escrúpulos religiosos afetarem as questões militares de outros povos ${ }^{57}$,

E. Mary. The Legislation of Hadrian and Antoninus Pio against circumcision. Latomus, v. 18, Fasc. 2, p. 334-347, Avril/Juin 1959; The Bar Kokhba Revolt and Circumcision: Historical evidence and Modern apologetics. In: OPPENHEIMER, Aharon (Hg). Jüdische Geschichte in hellenistisch-römischer Zeit: Wege der Forschung: Vom alten zum neuen Schürer. München: Oldenbourg, 1999. p. 119-132.

${ }^{50} \mathrm{O}$ shabbat judaico é um preceito religioso de se guardar o último dia da semana (sábado) mediante o descanso. Esse preceito é um dos elementos fundamentais da lei judaica, estando presente nos Dez Mandamentos (Êx 20.8-11), reafirmado em Deuteronômio (Dt 5.12-15; cf. Êx 31.14-15; 34.21; Lv 19.3), assim como aprofundado por Jeremias (17.19-27) e Neemias (10.31; 13.15-22). A seriedade do preceito é aferida na Bíblia Hebraica pelo relato de um homem que é morto por apanhar lenha no dia de sábado (Nm 15.32-36). Cf. SANDERS, E. P. Judaism: Practice and Belief, 63 BCE - 66 CE. London: SCM; Philadelphia: Trinity, 1992. p. 208-211.

51 BAR-KOCHVA, 2010, p. 123.

52 BAR-KOCHVA, 2010, p. 123. Sobre a tomada de Jerusalém por Ptolomeu I, cf. Flávio Josefo, Ant. Jud., 12.1.1; Cont. Ap., 1.205-211.

53 Este elemento, do respeito ao sábado inferindo no cuidado em não se tomar em armas, parece ter um eco no texto de Mateus 24.20, quando Jesus, referindo-se a uma invasão a Jerusalém, diz aos seus discípulos que orem para que a mesma não ocorra no inverno ou no sábado. Sobre esse texto, cf. SHEA, William H. The Sabbath in Matthew 24:20. Andrews University Seminary Studies, v. 40, n. 1, p. 23-35, Spring 2002. p. 23-35.

54 "A restrição mais potencialmente danosa na questão militar era o tabu contra lutar durante o ano sabático" (GOODMAN, M. D.; HOLLADAY, A. J. Religious scruples in Ancient warfare. Classical Quarterly, New Series, v. 36, n. 1, p. 151-171, 1986. p. 166).

${ }^{55}$ Cabe se destacar esse caso que, estando os mártires dentro da caverna no dia de sábado, é possível que a profanação ao sábado fosse não somente a guerra ao sábado, mas já o ato de sair da caverna, cf. Êx 16.29; $C D$ 10.20-21, 11.14-15. Cabe lembrar, porém, que em 1 Macabeus "esses judeus são apresentados como justos e piedosos, mas sua morte não é dada como exemplo, e sua escolha é implicitamente criticada, em nome do realismo". BERTHELOT, Katell. L'idéologie maccabéenne: entre idéologie de la résistance armée et idéologie du martyre. Revue des Études juives, v. 165, n. 1-2, p. 99-122, janvier/juin 2006. p. 105.

56 Acompanhando 1 Macabeus, Josefo também indica a mudança em relação à guerra no sábado, a partir dos macabeus: Flávio Josefo, Ant. Jud., 12.272-276. 2 Macabeus trata a questão de modo diferente. Cf. 2Mac 5.27. Sobre a importância dos macabeus na transformação da concepção judaica a respeito do sábado, cf. BORCHARDT, Francis. Sabbath Observance, Sabbath Innovation: The Hasmoneans and their Legacy as Interpreters of the Law. Journal for the Study of Judaism, v. 46, p. 159-181, 2015.

57 Apesar dos escrúpulos religiosos afetarem as questões militares para além da cultura judaica (como no exemplar caso dos espartanos), a peculiaridade judaica gerou, pelo menos a um primeiro momento, uma 
não chegaram à proporção do caso judaico. ${ }^{58}$ Apesar de ser possível que a ausência do sábado seja decorrente de uma omissão de Diodoro, é bastante improvável, uma vez que se trata de um elemento particularmente importante na invasão de Pompeu (contexto de seu relato), pois os judeus não se defenderam enquanto eram construídos os aríetes de guerra, já que não lhes era permitido lutar em dia de sábado, senão como evidente autodefesa. ${ }^{59} \mathrm{~A}$ ausência do sábado no relato, portanto, é provavelmente resultado de um simples desconhecimento por parte de Hecateu.

Apesar da negação da monarquia em 40.3 .5 poder ser resultante de uma má formulação da frase por Hecateu, não estando claro se ele fala que "nunca houve" ou "nunca há" um rei dos judeus ${ }^{60}$, há uma ausência a qualquer menção aos reis da história judaica, muitos deles importantes como Davi e Salomão. Mas o que levou Hecateu a esse furo em seu relato? Segundo Doron Mendels ${ }^{61}$, a ideia de Hecateu é o resultado do fato de que ele teria se informado com judeus egípcios críticos ao reinado da Judeia, que teriam ocultado a presença dos reis da história dos judeus que relataram. Tal intervenção não é apenas difícil como improvável, principalmente quando se considera que, tanto no período persa como no helenístico, "não há traços reais de oposição judaica à monarquia" 62 . É claro que houve críticas à monarquia, assim como haverá (séculos depois de Hecateu) uma oposição de muitos judeus à dinastia dos asmoneus, porém essa oposição não é nunca generalizada contra a monarquia em si, até porque o próprio messianismo se relacionava estreitamente com a monarquia. ${ }^{63} \mathrm{~A}$ possibilidade

espécie de referência enquanto estratégia militar. A respeito da influência dos escrúpulos religiosos nas questões militares do mundo antigo, cf. GOODMAN; HOLLADAY, 1986. Sobre a estratégia militar de ataques aos judeus nos sábados, cf. JOHNS, Alger F. The Military Strategy of Sabbath attacks on the Jews. Vetus Testamentum, v. 13, Fasc. 4, p. 482-486, Oct. 1963.

${ }^{58}$ Um dos grandes ícones gentílicos na ênfase do sábado como uma superstição foi Agatarquides de Cnido, porém cabe destacar que, como Josefo indica em seu Contra Apionem (2.40), os judeus ficaram amplamente conhecidos pela particularidade do sábado. Isso se comprova pela presença desse elemento nas descrições dos autores latinos a respeito dos judeus. Sobre Agatarquides e o sábado, cf. BAR-KOCHVA, 2010, p. 280-305. A respeito do sábado entre autores latinos, cf. HUGH MICHAEL, J. The Jewish Sabbath in the Latin Classical Writers. American Journal of Semitic Languages and Literatures, v. 40, n. 2, p. 117-124, jan. 1924.

59 Cabe destacar que, segundo Josefo, mesmo no período aasmoneu havia o cuidado de não se lutar no dia do sábado, senão como autodefesa, de modo que João Hircano cancelou um cerco pela aproximação do ano sabático (Flávio Josefo, Bel. Jud., 1.157-160), assim como os judeus não se defenderam da construção de aríetes de guerra por Pompeu (Flávio Josefo, Bel. Jud., 1.145-147; Dio Cassio, Historia Romana, 37.16.2), pois não era um ataque direto (SANDERS, 1992, p. 209).

${ }^{60}$ Como SCHWARTZ (2003, p. 194) aponta, não está claro no texto de Hecateu se os judeus "nunca tiveram um rei", ou se "nunca têm um rei (ultimamente? Idealmente?)". Bar-Kochva traduziu a passagem que se refere a essa ausência como "[there] never [has been] a king of the Jews", e Austin: "the Jews have never had a king". Walton, porém, traduz como "the Jews never have a king", de modo semelhante Whittaker: "was never to be a king of the Jews".

${ }^{61}$ MENDELS, 1983, p. 100-101.

62 BAR-KOCHVA, 2010, p. 122.

63 Sendo o Messias claramente da linhagem de Davi, surge o problema decorrente do fato que os asmoneus (dinastia que sobe ao poder pela Revolta dos Macabeus) não eram dessa linhagem real. Assim, há uma relativização em sua legitimidade, de modo que mesmo no livro de 1 Macabeus, que não somente tem os macabeus em alta conta como lhes promove, parece haver certo cuidado na aferição monárquica. Apesar 
indicada por Bar-Kochva, portanto, nos parece mais provável: como está evidente no próprio relato (40.3.5), a afirmação de que os judeus nunca tiveram um rei é "resultado do papel do sumo sacerdote, previamente descrito em muitos detalhes" ${ }^{" 94}$, ou seja, é uma dedução lógica do próprio Hecateu. ${ }^{65} \mathrm{Hecateu}$, buscando evidenciar as diferenças entre egípcios e judeus, deu ênfase à particularidade judaica do sumo sacerdócio, deixando de lado a presença da monarquia na história dos judeus. ${ }^{66}$ Assim, a posterior caracterização do regime judaico como uma "teocracia” terá em Hecateu seu primeiro passo $^{67}$, afinal, é aos sacerdotes, e não a um rei, que os judeus se curvam $(40.3 .6)^{68}$.

\section{Considerações finais}

A partir do estudo realizado sobre o relato de Hecateu de Abdera a respeito dos judeus, pode-se perceber que o período helenístico foi marcado por intensas interações culturais, evidenciadas não somente pelo interesse desse etnógrafo pelos judeus, mas ainda pelo provável contato com judeus egípcios que, reformulando sua própria

de Jonathan A. Goldstein defender que 1 Macabeus substitui a monarquia messiânica davídica pela dinastia dos asmoneus, John J. Collins responde afirmando que na verdade o messianismo é adiado, enquanto Choi nega que haja mesmo uma defesa da legitimidade real dos asmoneus em 1 Macabeus. De fato, em 1 Macabeus há tanto um elogio ao fato dos romanos não terem reis (1Mac 8.14), quanto o título real não é aferido a Simão (1Mac 14.41-42). Cf. CHOI, Dongbin. Are the Hasmoneans legitimized as Kings in 1 Maccabees? Dissertação (Mestrado em Teologia e Ciências da Religião) - Universidade de Nottingham, 2013; COLLINS, John J. Messianism in the Maccabean Period. In: NEUSNER, Jacob; GREEN, William S.; FRERICHS, Ernest. Judaism and their Messiahs at the Turn of the Christian Era. Cambridge: Cambridge University Press, 1987. p. 97-110; GOLDSTEIN, Jonathan A. How the Authors of 1 and 2 Maccabees treated the "Messianic Promises". In: NEUSNER, Jacob; GREEN, William S.; FRERICHS, Ernest. Judaism and their Messiahs at the Turn of the Christian Era. Cambridge: Cambridge University Press, 1987. p. 69-96.

64 BAR-KOCHVA, 2010, p. 122.

${ }^{65}$ Como bem indicado por Bar-Kochva, as preposições utilizadas por Hecateu em vários momentos indicam que aquilo que lhes precede é um fato histórico, e o que lhes sucede é uma conclusão do próprio autor a partir destes fatos. Assim, não somente a preposição diò kaì neste caso (40.3.5) faz esse papel como ainda: dià tò (40.3.3); dià tó / dià gàr (40.3.4); kai di' (40.3.8), cf. 40.3.5. Cf. BAR-KOCHVA, 2010, p. 122 n96.

${ }^{66} \mathrm{O}$ aspecto monárquico era uma das principais características dos egípcios, uma vez que tiveram uma tradição milenar de monarquia comandada pelos faraós, marcando diferença para com os gregos, com tradição democrática bastante forte - apesar da presença de monarquias como a diarquia espartana e mesmo os reis dos períodos homérico e helenístico. Tal importância tem como consequência, por exemplo, o fato de que os ptolomeus não serão retratados somente como "reis", mas propriamente como "reis do Egito”. Cf. MURRAY, 1970, p. 169. Cf. também o relato do reinado faraônico por Hecateu (Diod. Sic., Bib. Hist., 1.70-75).

${ }^{67}$ A afirmação que "o regime judaico na verdade é descrito por Hecateu como uma teocracia" (BAR-KOCHVA, 2010, p. 133), nos parece um exagero. Cf. BAR-KOCHVA, 2010, p. 135. A primeira aparição do termo se dá com Flávio Josefo (Cont. Ap., 2.165), cf. RODRIGUES, Nuno Simões. Flávio Josefo e a "invenção" da teocracia. Humanitas, v. LII, p. 195-212, 2000.

${ }^{68} \mathrm{O}$ aspecto de se curvar, colocando-se ao chão, não é bem visto pelos gregos. Os gregos tinham o ato de curvar-se (proskyneîn) como "uma marca da subserviência bárbara” (GRUEN, 1998, p. 100). Cf. Arriano, Anabasis, 4.11.9; Heród., Hist., 1.119,134; 8.118; Xen., Anab., 3.2.13; Cyr., 5.3.18; Plutarco, Themistocles, 27; Êx 12.27. 
história, forneceram a Hecateu o material necessário para esse escrever uma verdadeira interpretação grega tanto do êxodo judaico do Egito como ainda da formação da cultura e religião judaicas, mediante o uso da figura de Moisés como um legislador ao estilo grego, não somente instituindo a constituição dos judeus, como ainda empreendendo campanhas militares e organizando a vida social e política desse povo. Os supostos equívocos no relato, assim, não são erros propriamente ditos, mas antes readequações da história judaica a um público helênico, de modo a serem estabelecidos paralelos e padrões, a fim de que a cultura judaica fosse mais compreensível. Deste modo, a identidade judaica aparece em contraste não somente com gregos, mas ainda com egípcios, estabelecida sobre particularidades tais como sua religião e sua forma de governo, ao mesmo tempo que fronteiras culturais importantes como a circuncisão e o sábado não aparecem no relato, evidenciando (aparentemente) não serem entendidas dessa forma por Hecateu de Abdera, enfatizando assim a importância do período helenístico, no qual ambos aspectos culturais se tornarão cada vez mais proeminentes e definidores da identidade judaica, não somente para as demais culturas, como ainda para os próprios judeus.

\section{Referências}

AUSTIN, M. M. The Hellenistic World from Alexander to the Roman Conquest: A selection of ancient sources in translation. Second augmented edition. Cambridge: Cambridge University Press, 2006.

BAR-KOCHVA, Bezalel. Pseudo-Hecataeus, “On the Jews": Legitimizing the Jewish Diaspora. Berkeley: University of California Press, 1996.

The Image of the Jews in Greek Literature: The Hellenistic Period. Berkeley: University of California Press, 2010.

BERTHELOT, Katell. L'idéologie maccabéenne: entre idéologie de la résistance armée et idéologie du martyre. Revue des Études juives, v. 165, n. 1-2, p. 99-122, janvier/juin 2006.

BOLIN, Thomas M. The Making of the Holy City: on the foundations of Jerusalem in the Holy Bible. In: THOMPSON, Thomas L. (ed.). Jerusalem in Ancient History and Tradition. London; New York: T\&T Clark International, 2003. (Journal for the Study of the Old Testament Supplement Series, 381; Copenhagen International Seminar, 13). p. 171-196.

BORCHARDT, Francis. Sabbath Observance, Sabbath Innovation: The Hasmoneans and their Legacy as Interpreters of the Law. Journal for the Study of Judaism, v. 46, p. 159-181, 2015.

BREMMER, Jan N. Spartans and Jews: abrahamic cousins. In: GOODMAN, Martin; VAN KOOTEN, George H.; VAN RUITEN, Jacques T. A. G. M. Abraham, the Nations, and the Hagarites: Jewish, Christian, and Islamic perspectives on Kinship and Abraham. Leiden: Brill, 2010. p. 47-59.

CHOI, Dongbin. Are the Hasmoneans legitimized as Kings in 1 Maccabees? 2013. 62 f. Dissertação (Mestrado em Teologia e Ciências da Religião) - Universidade de Nottingham, 2013. COHEN, Shaye J. D. From the Maccabees to the Mishnah. 2. ed. Louisville: Westminster John Knox, 2006.

COLLINS, John J. Messianism in the Maccabean Period. In: NEUSNER, Jacob; GREEN, William S.; FRERICHS, Ernest. Judaism and their Messiahs at the Turn of the Christian Era. Cambridge: Cambridge University Press, 1987. p. 97-110.

DABROWA, Edward. The Hasmoneans and the Religious Homogeneity of their State. Scripta Judaica Cracoviensia, Krákow, v. 8, p. 7-14, 2010. 
DORAN, Robert. The Persecution of Judeans by Antiochus IV: The Significance of "Ancestral Laws". In: HARLOW, Daniel C. et al. The "Other" in Second Temple Judaism: Essays in Honor of John J. Collins. Grand Rapids: Eerdmans, 2011. p. 423-433.

FALBEL, Nachman. Raízes do anti-semitismo na Antiguidade e na Idade Média. In: FUKS, Saul (Org.). Tribunal da história. Rio de Janeiro: Imago; Centro de História e Cultura Judaica, 2008. v. 2: Processos de formação da identidade judaica e do anti-semitismo, p. 197-227.

FAUST, Avraham. The Bible, Archaeology, and the practice of circumcision in Israelite and Philistine Societies. Journal of Biblical Literature, v. 134, n. 2, p. 273-290, 2015.

FREUD, Sigmund. Moisés e a religião monoteista. Tradução Paulo Samuel. Lisboa: Guimarães, 1990.

GAGER, John G. Some Thoughts on Greco-Roman Versions of the Exodus Story. Jewish History, v. 12, n. 1, p. 129-132, Spring 1998.

GOLDSTEIN, Jonathan A. How the Authors of 1 and 2 Maccabees treated the "Messianic Promises". In: NEUSNER, Jacob; GREEN, William S.; FRERICHS, Ernest. Judaism and their Messiahs at the Turn of the Christian Era. Cambridge: Cambridge University Press, 1987. p. 69-96. GOODMAN, M. D.; HOLLADAY, A. J. Religious scruples in Ancient warfare. Classical Quarterly, New Series, v. 36, n. 1, p. 151-171, 1986.

GRUEN, Erich S. The Use and Abuse of the Exodus Story. Jewish History, v. 12, n. 1, p. 93122, Spring 1998.

HENGEL, Martin. Judaism and Hellenism: Studies in their Encounter in Palestine during the Early Hellenistic Period. Philadelphia: Fortress, 1974. v. 1.

HUGH MICHAEL, J. The Jewish Sabbath in the Latin Classical Writers. American Journal of Semitic Languages and Literatures, v. 40, n. 2, p. 117-124, Jan. 1924.

JAEGER, Werner. Greeks and Jews: The first Greek records of Jewish religion and civilization. Journal of Religion, v. 18, n. 2, p. 127-143, April 1938.

JOHNS, Alger F. The Military Strategy of Sabbath attacks on the Jews. Vetus Testamentum, v. 13, Fasc. 4, p. 482-486, Oct. 1963.

KALLAI, Zecharia. The Twelve-Tribe Systems of Israel. Vetus Testamentum, v. 47, Fasc. 1, p. 53-90, Jan. 1997.

LUDLAM, Ivor. Appendix: The God of Moses in Strabo. In: BAR-KOCHVA, Bezalel. The Image of the Jews in Greek Literature: The Hellenistic Period. Berkeley: University of California Press, 2010. p. 525-541.

MURRAY, Oswyn. Hecataeus of Abdera and Pharaonic Kingship. Journal of Egyptian Archaeology, v. 56, p. 141-171, Aug. 1970.

NA'AMAN, Nadav. The Canaanites and their Land: A Rejoinder. In: DIETRICH, Manfried; LORETZ, Oswald. (Hg.). Sonderdruck aus Ugarit-Forschungen: Internationales Jahrbuch für die Altertumskunde Syrien-Palästinas. Neukirchen-Vluyn: Butzon \& Bercker, 1994. p. 397-418. NIEHOFF, Maren R. Circumcision as a marker of identity: Philo, Origen and the Rabbis on Gen 17:1-4. Jewish Studies Quarterly, v. 10, n. 2, p. 89-123, 2010.

REINACH, Théodore. Textes d'auteurs grecs et romains relatifs au judaïsme. Reunis, traduits et annotés par Théodore Reinach. Paris: Ernest Leroux, 1895. (Fontes rerum Judaicarum).

RODRIGUES, Nuno Simões. Flávio Josefo e a "invenção" da teocracia. Humanitas, v. LII, p. 195-212, 2000.

SANDERS, E. P. Judaism: Practice and Belief, 63 BCE - 66 CE. London: SCM; Philadelphia: Trinity, 1992.

SCHÄFER, Peter. Judeophobia: Attitudes toward the Jews in the Ancient World. Cambridge: Harvard University Press, 1997. 
SCHÄFER, Peter. The Bar Kokhba Revolt and Circumcision: Historical evidence and Modern apologetics. In: OPPENHEIMER, Aharon (Hg). Jüdische Geschichte in hellenistisch-römischer Zeit: Wege der Forschung: Vom alten zum neuen Schürer. München: Oldenbourg, 1999. p. 119-132. SCHWARTZ, Daniel R. Diodorus Siculus 40.3 - Hecataeus or Pseudo-Hecataeus? In: MOR, Menahem et al. (eds.). Jews and Gentiles in the Holy Land in the Days of the Second Temple, the Mishnah and the Talmud: a collection of articles. Jerusalem: Yad Ben-Zvi, 2003. p. 181-197. SHEA, William H. The Sabbath in Matthew 24:20. Andrews University Seminary Studies, v. 40, n. 1, p. 23-35, Spring 2002.

SMALLWOOD, E. Mary. The Legislation of Hadrian and Antoninus Pio against circumcision. Latomus, v. 18, Fasc. 2, p. 334-347, Avril/Juin, 1959.

STERN, Menahem. Greek and Latin Authors on Jews and Judaism. Edited with Introductions, Translations, and Commentary by Menahem Stern. Jerusalem: Israel Academy of Sciences and Humanities. 3 v.: 1976 (I); 1980 (II); 1984 (III). (Fontes ad res judaicas spectantes).

STERN, Sacha. Jewish Identity in Early Rabbinic Writings. Leiden: E. J. Brill, 1994.

VAN SETERS, John. Solomon's Temple: Fact and Ideology in biblical and Near Eastern Historiography. Catholic Biblical Quarterly, v. 59, n. 1, p. 45-57, Jan. 1997.

WALTON, F. R. Diodorus of Sicily. Cambridge, Mass.; London: Harvard University Press, 1967. v. 12. (Loeb Classical Library, 409).

WHITTAKER, Molly. Jews and Christians: Graeco-Roman Views. Cambridge: Cambridge University Press, 1984. 